\title{
Communication, engagement and science-based policy
}

Anne Megaro, Director of Government and Community Relations, UC Agriculture and Natural Resources

A s a prospective graduate student, I applied to an animal science Ph.D. program knowing that I wasn't going to pursue a career as a bench researcher. This move was unconventional, but I had a plan: I wanted the knowledge, experience and credibility of a doctoral degree so that I could help bridge the communication gap between scientists and nonscientists. To achieve this goal, I would have to leave the laboratory and learn how to communicate with the public in a meaningful and effective way.

This desire led to a career in the realm that is the focus of this special issue of California Agriculture: the research-topolicy process - through which, ideally, scientific expertise informs the development of sound policies that further the public good.

As a congressional science and technology policy fellow, a consultant to the Agriculture Committee in the California State Senate, and now as the Anne Megaro director of government and community relations for UC Agriculture and Natural Resources (UC ANR), I have experienced from multiple angles the lessons that Gupta, Campbell and Cole-Weiss articulate in their stage-setting article for this issue (page 11). That is, that the value that scientists - and, in particular, Cooperative Extension scientists - bring to the policymaking process is tied to their ability to communicate science effectively to many audiences and engage with a wide range of stakeholder groups.

I'd argue that UC ANR, and indeed Cooperative Extension nationally, is well positioned to expand this research-to-policy role.

First is the issue of communication. Helping and encouraging scientists to translate their work into something accessible to the general public is crucial. By accessible, I mean sharing science in a way that is relatable and in which people can understand and apply to their own lives. Cooperative Extension academics already excel at this skill. Their work by its nature involves delivering research into the hands and minds of practitioners and the public so that it can be applied immediately in the real world, in real time.

Cooperative Extension academics also tend to be expert relationship-builders. Their success as extension scientists is built on establishing trusted relationships with community groups, farmers and land managers. Those same skills can — and should - be applied to developing relationships with policymakers and others involved in the policymaking process.

This special issue - developed with guest editors Clare Gupta and Leslie Roche, both UC Cooperative Extension Specialists at UC Davis - emerged from the work of the UC ANR Research to Policy Program Team. This group has created a community of practice and provided a forum for sharing policy work, bringing together UC ANR academics and staff to learn from colleagues how to overcome challenges and implement best practices for policy engagement.

The articles in this special issue illustrate some of the many ways in which UC ANR research and extension work continues to inform and develop evidencebased policy in California. They document how good science coupled with communication and engagement have helped to expand the safe use of prescribed fire in forests, limit the water quality impacts of dairy farms, better manage our streams and rivers, improve nutrition standards and policies, and increase the efficiency of water use in urban landscapes.

As you read these articles, I invite you to think about how you can be involved in public policy, whether you are a researcher or member of the public. How do you bridge the gap between scientists and policymakers? What can you, as an individual, do to engage in evidence-based policymaking? CA

Anne Megaro is the Director of Government and Community Relations for UC Agriculture and Natural Resources. She helps bench and field researchers spread the good news of their work by sharing their story with policymakers and community stakeholders. She earned a Ph.D. in animal science from Cornell University and was a 2010-2011 AAAS Science and Technology Policy Fellow in the U.S. House of Representatives. Prior to her current role, she most recently served as Consultant for the Senate Agriculture Committee for the State of California. 